\title{
Missing the Boat on Invasive Alien Species: A Review of Post-Secondary Curricula in Canada
}

\author{
Andrea L. Smith \\ Dawn R. Bazely \\ Norman D. Yan \\ York University
}

\begin{abstract}
Invasive alien species (IAS) cause major environmental and economic damage worldwide, and also threaten human food security and health. The impacts of IAS are expected to rise with continued globalization, land use modification, and climate change. Developing effective strategies to deal with IAS requires a collaborative, interdisciplinary approach, in which scientists work co-operatively with social scientists and policy-makers. Higher education can contribute to this process by training professionals to balance the ecological, economic, and social dimensions of the IAS problem. We examined the extent of such training in Canada by reviewing undergraduate and graduate university curricula at all 94 member institutions of the Association of Universities and Colleges of Canada for IAS content. We found that degree and diploma programs focusing on IAS issues are lacking at Canadian post-secondary institutions. Furthermore, few courses are devoted solely to IAS, and those that are typically adopt an ecological perspective. We argue that the absence of interdisciplinary university curricula on IAS in Canada negatively affects our ability to respond to this growing global challenge. We present several international educational programs on IAS as case studies on how to better integrate training on invasive species into university curricula in Canada.

\section{RÉSUMÉ}

Les espèces exotiques envahissantes (EEE) sont à l'origine d'importants dommages écologiques et économiques partout dans le monde, en plus de menacer la sécurité alimentaire et la santé humaine. On s'attend à ce que leurs effets prennent de l'ampleur devant la poursuite de la mondialisation, l'évolution de l'utilisation des sols et les changements climatiques. L'élaboration de stratégies efficaces pour contrer les EEE exige une approche coopérative et interdisciplinaire, par laquelle des scientifiques travaillent encollaboration avecdes spécialistes en sciences sociales et des responsables de l'élaboration de politiques. L'enseignement
\end{abstract}


supérieur peut y contribuer en formant des professionnels à trouver un équilibre entre les dimensions écologiques, économiques et sociales du problème des EEE. Nous avons étudié la portée d'une telle formation au Canada en révisant les programmes d'études universitaires des premier et second cycles de chacun des 94 établissements membres de l'Association des universités et collèges du Canada. Nous en avons conclu que les programmes menant à un grade ou à un diplôme et ciblant les problèmes liés aux EEE font défaut aux établissements postsecondaires canadiens. En outre, peu de cours se concentrent uniquement sur les EEE, et ceux qui le font adoptent habituellement une approche écologique. Nous faisons valoir que le manque de programmes universitaires interdisciplinaires portant sur les EEE au Canada entrave notre capacité à affronter ce défi mondial croissant. Nous présentons plusieurs programmes éducatifs internationaux sur les EEE, à titre d'études de cas pour mieux intégrer la formation sur les espèces envahissantes aux programmes universitaires du Canada.

\section{INTRODUCTION}

An inevitable consequence of globalization has been increased biotic exchange worldwide, as rising international trade and travel introduce species to new areas, both intentionally and accidentally (Myers \& Bazely, 2003). While the movement of organisms is a natural process, the rate, magnitude, and geographic scale of current biological introductions far exceed historical patterns of range expansion (Lodge, 1993) and are driven by human activity (Larson, 2007). Only a small percentage of introduced species actually become established, and even fewer become harmful or invasive (Williamson \& Brown, 1986). Nonetheless, the impacts of invasive alien species (IAS) are dramatic, extensive, and often irreversible, and include threats to biodiversity, food security, health, and economic development (McNeely, 2001).

IAS are considered the second greatest driver of biodiversity loss after habitat degradation (Sala et al., 2000; Simberloff, Parker, \& Windle, 2005). Once IAS become established, they typically spread rapidly in the absence of natural predators, disease, and competition (Sax et al., 2007). Impacts on native ecosystems and species vary, but can include habitat change, competition, predation, herbivory, disease, and hybridization (Simberloff, 2002). Associated disruption of ecosystem function and services (e.g., hydrological capacity, seed dispersal, nutrient cycling) can have profound effects on the economy and food production, while the spread of infectious disease poses significant concerns for human health (Colautti, Bailey, van Overdijk, Amundsen, \& MacIsaac, 2006; Enserink, 1999). The global homogenization of biodiversity also threatens human cultural practices and values, such as traditional hunting and fishing, and nature appreciation (Pfeiffer \& Voeks, 2008). The ecological and socio-economic costs of dealing with IAS are thus immense, and, to a large extent, self-perpetuating (McNeely, Mooney, Neville, Schei, \& Waage, 2001). Even if efforts to halt the introduction of new IAS are successful, established populations continue to cause damage, and are often difficult, if not impossible, to eradicate.

Biological invasions are predicted to increase worldwide as opportunities for species to spread and establish proliferate. In particular, continued trade liberalization and tourism will provide numerous pathways for IAS to reach new destinations, and interactions with other elements of global change, such as land-use modification and climate change, will likely enhance IAS success once they arrive (McNeely, 2000; Mooney \& Hobbs, 2000; Sutherst, 2000).

Clearly, IAS represent a complex global problem that demands a comprehensive, coordinated, and multi-faceted response. Like other pressing environmental issues (e.g., climate change, pollution, resource overexploitation), the IAS problem challenges scientists to re-evaluate their role in society from mere providers of facts to active participants in the formation of public policy (Larson, 2007; Norton, 1998; Noss 2007). At the same time, the broad threats posed by IAS necessitate a collaborative, interdisciplinary approach, in which scientific knowledge is integrated with insights from other disciplines and perspectives. As McNeely et al. (2001) suggest, the IAS issue "presents an unparalleled opportunity to respond with actions that link preservation of biodiversity with protection of the health and livelihood of the world's human populations" (p. viii). Strategies to control and manage IAS will only be effective if they succeed in addressing ecological, economic, and social considerations (Mooney \& Hobbs, 2000). 
Higher education has a significant role to play in the promotion of an interdisciplinary and cooperative approach to IAS issues. Universities are increasingly recognized as having both a unique responsibility and a unique opportunity to prepare students for the growing complexity of global problems (Godemann, 2008; Sterling \& Witham, 2008). Training to deal with global challenges, however, must be broader and deeper than traditional disciplinary education because environmental problems typically span multiple academic disciplines and societal issues (Ludwig, Mangel, \& Haddard, 2001). Science plays a critical role in defining the nature of environmental issues, but, since root causes often are anthropogenic, solutions to these problems must ultimately come from a blend of science and socio-economic perspectives (Godemann, 2006). Additionally, addressing many environmental problems necessitates the participation of non-academic practitioners, working in concert with academics, in a transdisciplinary approach. As a result, the traditional disciplinary structure of academia is being challenged as an impediment to the cross-pollination, collaboration, and integration of knowledge required for interdisciplinary and transdisciplinary learning and research (Haigh, 2005).

Recent IAS management models propose ways to bridge the gap between science and society, and offer promise for interdisciplinary education on IAS issues. Tanentzap, Bazely, Williams, and Hoogensen (2009) suggest that, by framing IAS in the context of human security, both ecological and socio-economic impacts can be more effectively articulated to policy-makers and the general public, and management priorities can be developed consistent with societal needs, such as economic wellbeing. Ricciardi, Palmer, and Yan, meanwhile, argue that since the impacts of IAS tend to be well understood and predictable, but essentially uncontrollable, IAS can be viewed as analogous to natural disasters, and should be managed as such. IAS management strategies thus should focus on prevention by incorporating scientific knowledge on sources and pathways of introduction with policing of pathways (e.g., through legislation, monitoring, and enforcement), and public education to empower individuals to stop the spread of IAS.

Given the broad and increasing threats of IAS to the environment and society, in this paper we explore how well we are training professionals in Canada to deal with the complex interdisciplinary challenges of IAS, and compare our efforts with educational programs offered internationally. In particular, we review undergraduate and graduate university curricula from across the country and internationally to address the following questions:

1. Do degree or diploma programs exist that focus specifically on the significant global environmental challenge of IAS?

2. Do programs and/or individual courses approach IAS issues from an interdisciplinary perspective?

3. Is training on IAS offered within a human security and/or natural disaster framework?

4. Does interdisciplinary training on IAS issues exist internationally that could be used as a model to improve educational preparedness in Canada?

\section{METHODS}

We conducted an online review of all 94 member institutions of the Association of Universities and Colleges of Canada (AUCC) to assess the degree to which IAS issues are addressed at both the undergraduate and graduate level nationally. The review was conducted between February and July 2009. We began by examining each institution's webpage for all faculties, departments, and programs that related to the following general disciplines: Agriculture, Anthropology, Biology, Disaster and Emergency Management, Environmental Law, Environmental Studies, Environmental Science, Forestry, Public Health, Public Policy, and Sustainability. To ensure no relevant training programs or courses were overlooked, we also performed a search of the AUCC's online Directory of Canadian Universities Database (http://oraweb.aucc.ca/dcu_e.html) for programs of study in both English and French, co-op and non co-op, at all program levels, and at all member institutions for the following fields of study: agriculture, general; biological and physical sciences; biology/biological sciences, general; conservation biology; ecology; energy, environmental, and natural resources law; environmental biology; environmental health; environmental science; environmental studies; fishing and fisheries science and management; forest management/forest resource management; geography; international/global studies; multidisciplinary/interdisciplinary studies; natural resource economics; natural 
resources/conservation, general; natural resources management and policy; natural sciences; plant protection and integrated pest management; public policy analysis; science, technology and society; security and protective services; water, wetlands and marine resources management; and wildlife and wildlands science and management.

Information was compiled regarding the number of degree and diploma programs that cover environmental issues in general, the number of degree and diploma programs that focus specifically on IAS issues, the number of programs and/or courses approaching IAS challenges from an interdisciplinary perspective, and the coverage of IAS in human security and/or disaster management programs.

The following international education programs were also profiled as case studies for the interdisciplinary training of IAS issues:

- Global Linkages of Biology, the Environment and Society (University of Notre Dame, USA);

- Responding to Rapid Environmental Change (University of California-Davis, USA);

- Risk Analysis for Introduced Species and Genotypes (University of Minnesota, USA);

- Postgraduate Diploma and Masters Degree in Biosecurity (University of Auckland, New Zealand).

\section{RESULTS}

\section{The Situation in Canada}

None of the AUCC member institutions offered degree or diploma programs, either at the undergraduate or graduate level, that focused specifically on IAS issues. Most universities had undergraduate and/or graduate programs in areas such as environmental science, environmental studies, natural resource management, and conservation biology, and thus may cover IAS issues in some capacity. However, few courses were found in our online search devoted primarily to IAS issues (but see below). Instead, IAS were commonly a topic of a single lecture or section in undergraduate and graduate biodiversity, conservation biology, or environmental science courses, or as possible seminar or essay topics in such courses.

Many programs at both the undergraduate and graduate level emphasize interdisciplinary training in themes related to IAS issues, including global change, natural resource management and biodiversity protection (e.g., Carleton University's BSc Integrated Science Program, McMaster University's Honours BSc Integrated Science Program, McGill University's Graduate Option in Environment, Simon Fraser University's Masters of Resource Management, and University of Winnipeg's Graduate Studies in BioScience, Technology and Public Policy). The interdisciplinary approaches taken by these different programs have several aspects in common. For example, programs typically promote problemsolving; creative and critical thinking; and a consideration of biological, physical, socio-cultural, and economic factors. Additionally, these programs highlight the complexity of environmental problems and the need to investigate their root causes, as well as the importance of designing innovative solutions, influenced by multiple perspectives. Many programs also examine the role of science in the policy process. Some programs are collaborative, offered jointly by faculties of Science and Humanities (e.g., University of Calgary's BSc Environmental Science Program). Brock University has an undergraduate program in Tourism and Environment, which combines study of environmental issues and sustainability with tourism, addressing problems created by the industry, such as pollution and loss of biodiversity. However, no course specifically on IAS exists in the program.

Our online review found only a handful of courses that focus primarily on IAS issues, and most of these examine the topic from a strictly ecological perspective. The University of Victoria offers a course in "Invasive Species Management" which covers ecological, social, and economic aspects of IAS as part of its Professional Specialist Certificate Program in Native Species and Natural Processes. Trent University offers a fourth year "Biology of Invasions" course, focusing on ecological adaptations contributing to the success of IAS. The University of Windsor offers a fourth year "Invasion Ecology" course, which examines the invasion process, from vectors to management. York University has a "Biology in Environmental Management" course for senior undergraduate and graduate students, which examines environmental protection and management in the context of pollution and IAS. McGill University has a senior undergraduate and graduate level course on the "Ecology of Species Invasions," which explores the causes and impacts of IAS, including risk assessment methods and management strategies. 
Four degree and diploma programs were found at AUCC institutions in the area of disaster management, but none of them explicitly mention IAS as a threat to human security or as a form of natural disaster (Brandon University's BA/ BSC Applied Disaster and Emergency Studies Program, Canadian Mennonite University's Concentration and Minor in Disaster Recovery Studies, Royal Roads University's MA in Disaster and Emergency Management, and York University's Certificate and MA in Emergency Management). All of these programs recognize the interdisciplinary nature of disaster management, and include courses in mitigation, risk analysis/management, and emergency response. Several programs have courses specifically on environmental disasters, of both natural and human origin. Brandon University's program recommends students complement their major with course offerings such as "Pollution Biology" and "Global Environmental Change," which may include coverage of IAS issues. However, IAS are not a core component of any of the currently existing disaster management programs.

As Table 1 illustrates, there are over 200 undergraduate, 100 graduate, and 30 diploma programs available at AUCC institutions that deal with global environmental problems. Courses offered within these programs typically address issues such as climate change, pollution, waste management, sustainable development, renewable resource management, and ecotoxicology, but significant coverage of IAS is noticeably absent from the curriculum. Our online review of post-secondary curricula undoubtedly missed courses and/or course modules that are not listed electronically. While more courses may exist that cover IAS issues, our survey nevertheless revealed that an overarching focus on the complex interdisciplinary threats of IAS is lacking in Canadian higher education.

Table 1: Number of degree, diploma, or certificate programs covering environmental issues at AUCC institutions. Each tally indicates one such program per institution.

\begin{tabular}{|c|c|c|c|}
\hline Program & Undergraduate & Graduate (M. Sc. or Ph. D) & Diploma or Certificate \\
\hline Agroecology & 2 & & \\
\hline Biology & 61 & 31 & 2 \\
\hline Biosystems and Biodiversity & 1 & 1 & \\
\hline Bioscience and Public Policy & 2 & 1 & \\
\hline Conservation & 5 & & \\
\hline Ecology & 13 & 2 & 4 \\
\hline Ecological Restoration and Rehabilitation & & & 2 \\
\hline Ecosystem Health & 1 & & \\
\hline Environment \& Business & 1 & & 1 \\
\hline Environment \& Sustainability & & 1 & 1 \\
\hline Environmental Biology & 9 & 1 & 1 \\
\hline Environmental Economics & 2 & 2 & \\
\hline Environmental Governance & 1 & & \\
\hline Environmental Impact Assessment & & 1 & 1 \\
\hline Environmental Management & 3 & 1 & 4 \\
\hline Environmental Practice & & & 1 \\
\hline Environmental Protection and Technology & 1 & & 2 \\
\hline Environmental Studies & 36 & 10 & 5 \\
\hline Environmental Science & 36 & 12 & 1 \\
\hline Environmental Science \& Public Health & 1 & & 1 \\
\hline Geography & 45 & 31 & 3 \\
\hline Global Resource Systems & 1 & & \\
\hline Integrated Land and Food & & 1 & \\
\hline Natural Resource Conservation & 3 & 1 & \\
\hline Natural Resources and Energy & & 1 & \\
\hline Natural Sciences & 1 & & \\
\hline Renewable Resources & & 3 & 1 \\
\hline Resource Management & 4 & 2 & 3 \\
\hline TOTAL & 229 & 102 & 33 \\
\hline
\end{tabular}




\section{The Situation Elsewhere}

Several U.S. graduate programs have been initiated in recent years through the National Science Foundation's Integrative Graduate Education and Research Traineeship (IGERT) funding framework that take an interdisciplinary approach to IAS issues. The goal of IGERT is to educate PhD students through interdisciplinary training, promoting collaborative research that crosses traditional disciplinary boundaries. While IGERT offers only short-term funding, available over several years, the intention of the traineeship is to catalyze a cultural change in graduate education that is longer lasting. Indeed, a recent evaluation of the funding program found that it lead to policy changes promoting interdisciplinary training and research at participating universities (e.g., through development of new courses, degree requirements, degrees and certificates, and through increased university support for interdisciplinary education; Carney, Chawla, Wiley, \& Young, 2006).

Global linkages of biology, the environment and society (GLOBES) IGERT (University of Notre Dame; http://globes.nd.edu). The GLOBES program aims to provide the biological, social, economic, legal, and ethical tools necessary to address pressing global environmental problems, such as climate change, poverty, and IAS. Faculty are drawn from a variety of university departments, including anthropology, biology, economics, history, law, philosophy, and theology. Students participate in GLOBES while fulfilling PhD requirements within their own home departments, and receive a GLOBES designation on their doctoral degree upon completion. The program's curriculum emphasizes a team-based interdisciplinary approach through courses, seminars, training modules, and a field research project. Students must take at least four GLOBES courses and three GLOBES training modules, and conduct a real world practicum to meet program requirements.

Among the GLOBES courses offered in 2009 were two that focus on IAS issues: "Humans and the Global Environment: Coevolution or Mutual Destruction?" and "Policy of Biological Invasions." The former devotes four lectures to IAS, examining the problem both from biological and anthropological perspectives. The latter focuses on policies affecting the movement of species across political boundaries, the extent to which current scientific understanding is adequately reflected in policies, and the extent to which scientific research contributes to improving existing policies. As part of the course, students examine a specific policy at either the international, national, state, or local level to address these questions, and provide recommendations for bridging the science-policy gap.

Training modules are offered to complement and expand upon students' primary research areas through cross-disciplinary training. Through this approach, students are exposed to alternative and diverse perspectives on problem-solving which may not be evident within their traditional study areas. Topics covered in the past have included communicating research to non-scientific audiences and the media, environmental economics, and using science to inform policy-makers.

To further transcend traditional research disciplines, the program offers students the opportunity to work as part of an interdisciplinary team on a field research project. The premise of the real world practicum is that environmental degradation (e.g., habitat destruction, biodiversity loss, pollution, and the spread of IAS) is caused and perpetuated by inter-related biological and social factors, and solving these problems requires co-operation between biological and social scientists, as well as experts in public policy and law. Students are organized into teams with faculty members and partner institutions to conduct research in areas such as IAS ecology, economics, and management in the U.S., Africa, and China. Field projects may augment dissertation work, or can be expanded to form the focus of doctoral research.

Responding to rapid environmental change (REACH) IGERT (University of California- Davis; http://reach.ucdavis.edu). The REACH IGERT evolved out of a previous IGERT program offered at UC-Davis on Biological Invasions, which ran from 2001 to 2008. The current program continues to address IAS issues, but also broadens the scope of training to encompass a larger suite of environmental problems caused by human-induced rapid environmental change, including climate change and habitat degradation. The goal of the program is to train graduate students in both the scientific and social dimensions of effective problem-solving and decision-making in a rapidly changing world. Faculty represent multiple university departments (e.g., Agricultural and Resource Economics, Civil and Environmental Engineering, Environmental Science and Policy, Evolution and Ecology, Law, Sociology and Wildlife, Fish and Conservation Biology) and non-university institutions (e.g., California 
Department of Food and Agriculture, California Department of Fish and Game, the Nature Conservancy). As with the GLOBES program, students enroll in a home department to carry out their PhD training, which is augmented by two years of REACH curriculum. The program consists of a core course, a multidisciplinary collaborative research project, and internships in the public and private sectors.

The first-year core course "Multidisciplinary Approaches to Rapid Environmental Change" introduces students to a range of disciplines influencing human response to rapid environmental change including environmental economics, environmental history, environmental ethics and justice, and law and policy. As part of the curriculum, students learn to communicate scientific issues to the public and media and to work with legislators.

In the second year of the REACH program, students work as a team to design and carry out a multidisciplinary research project focusing on a particular response to rapid environmental change. At the end of the year, students are expected to present their research results to the general public, stakeholders, and other students through symposia and other media. For example in past years, students have produced a film, published peer-reviewed papers, and developed high school curriculum related to the biological and social impacts of IAS.

Beyond the first two years of the program, students participate in a three-month internship and multidisciplinary research assistantships to promote collaboration and integration of multiple perspectives in their training. The non-academic internship may be held either within the U.S. or with an international partner institution, to foster experiential learning and collaboration across disciplinary and political boundaries. Opportunities are available within government agencies, the private sector, and environmental organizations both nationally and abroad (e.g., in Australia, Kenya, Spain etc.). Bridge research assistantships, meanwhile, allow graduate students to work closely with two or more trainers from different disciplines to "catalyze collaboration and institutionalize a culture of multidisciplinary research" (Strauss, Doremus, Griesemer, Grosberg, \& Rice, 2007, p. 15).

Risk analysis for introduced species and genotypes IGERT (University of Minnesota; http:// isg-igert.umn.edu). The goal of the Risk Analysis for Introduced Species and Genotypes program is to train graduate students to integrate scientific knowledge with societal concerns on invasive species and genetically modified organisms (GMOs) so that public policy and management strategies can be improved. In particular, the program aims to address the many training and communication gaps that exist amongst biologists, economists, and social scientists working on IAS and GMOs issues. For example, biologists often lack training on the societal and policy implications of their research, and how to apply science to solve real-world problems. Similarly, economists and social scientists may lack a basic understanding of ecological principles. The program has a significant focus on the value of sound ecological risk analysis (ERA) as a conceptual framework for assessing the ecological impacts of IAS and GMOs and for strengthening the decision-making process. Faculty and partners have diverse backgrounds in biology, risk analysis, policy, applied economics, public health, sociology, and statistics. External partners include the Minnesota Invasive Species Advisory Council, the U.S. Fish and Wildlife Service, and the United Nations Convention on Biodiversity. The program is offered as a minor option for both MSc and PhD students. Masters students must complete the first year of the program (comprised of a core course and workshop), as well as two semesters of roundtable discussions. Doctoral students must complete the full three-year program, which, in addition to the first year requirements, consists of a Problem-Solving Partnership Practicum (in year 2) and a Cooperative Learning Practicum and Workshop (in year 3). Additionally, doctoral dissertations must relate to the program's research themes, as outlined below.

Student training and research in the Introduced Species and Genotypes program is shaped by four main areas of inquiry:

1. Evaluating the effectiveness of current regulation at allowing or excluding new species and genotypes appropriately;

2. Improving theory and models for ERA;

3. Addressing uncertainty in risk assessments; and

4. Developing effective and environmentally sound management strategies.

Through the program, students gain skills to improve the scientific basis for decision-making on IAS and GMOs issues, and to successfully use this science to inform policy. An emphasis on collaborative, interdisciplinary learning and problem solving (the co-operative learning approach) enables 
students to link science with the needs of policy-makers and society. IGERT faculty are organized into eight interdisciplinary instructional teams to ensure a coherent integrated curriculum, with each team representing a cross-section of natural and social science expertise. Each team receives training in the co-operative learning approach and incorporates it into all program courses.

The first-year core course "Risk Analysis for Introduced Species and Genotypes" examines the fundamentals of ERA, including risk identification, characterization, and management. As part of the course, students conduct team projects to evaluate existing ERA as it applies to IAS and GMOs. Following completion of the course, students take part in a four-day Risk Analysis Modeling Workshop, and must take an additional quantitative modeling course offered by another graduate program (e.g., "Applied Microeconomics," "Stochastic Modeling and Analysis," or "Population Dynamics" etc.).

In the second year of the program, students design and conduct a 15-week collaborative research project to fulfill the Problem-Solving Practicum requirements. Each project is overseen by three faculty members drawn from different disciplines, and carried out in co-operation with one of the program's external partners. Research must fall under one of the four focal study areas outlined above, and must address a priority problem identified by the external partner. Students may expand on the practicum research for their dissertation.

In the third year, students participate in a Co-operative Learning Practicum, in which co-operative learning techniques relevant to ERA decision-making are presented. Students are required to develop an ERA teaching case based on their work the previous year in the Problem-Solving Practicum, which may be used subsequently in the first year core course.

Weekly roundtables offer students additional exposure to interdisciplinary thinking on IAS and GMOs issues. Each term a different research theme is adopted, and topics have included ethical issues, novel tools and approaches, emerging policy and regulatory issues, and new management approaches. Three annual gatherings are also organized to highlight research efforts and accomplishments, and to provide ongoing professional training (e.g., in co-operative learning, interdisciplinary research etc.).

Postgraduate diploma \& Masters degree in biosecurity (University of Auckland; http:// www.sbs.auckland.ac.nz/uoa/science/about/subjects/biosec.cfm). The University of Auckland is home to the international headquarters of the International Union for the Conservation of Nature's (IUCN) /Species Survival Commission's (SSC) Invasive Species Specialist Group, and also hosts a Centre for Biodiversity and Biosecurity. According to New Zealand's Biosecurity Strategy (2003), biosecurity is defined as "the exclusion, eradication or effective management of risks posed by pests and diseases to the economy, environment and human health" (Government of New Zealand, p. 5). The Biosecurity programs at the university are jointly offered by the School of Biological Sciences and the School of Geography, Geology and Environmental Science, and aim to introduce students to the interdisciplinary nature of biosecurity, with an emphasis on translating scientific discovery into tools for prevention and management of invasive species.

The Biosecurity Diploma program offers one year of training in invasion biology, with a primary focus on the ecological impacts of IAS, although economic and human health aspects are also covered. Students take three compulsory courses: "Biosecurity and Invasion Biology," "Weed and Pest Management," and "Biodiversity Management and Conservation," as well as five additional courses from biology and/or environmental management. As part of the "Biosecurity and Invasion Biology" course, students are required to prepare a report on a priority pest species as identified by the Auckland Regional Council's Regional Pest Management Strategy. In the report, students must review all information on the particular species to determine its threat as a potential IAS to New Zealand, known control or management methods, knowledge gaps, and research recommendations. The information is then used by biosecurity managers to prevent or control IAS species in the country.

The master's program requires the successful completion of the diploma curriculum in year 1 , followed by a thesis on a biosecurity topic in year 2 .

\section{DISCUSSION}

\section{The Need for Interdisciplinary Training on IAS}

IAS pose a significant threat to natural environments, biodiversity and human society, and their impacts are expected to multiply worldwide in the near future. The challenge of dealing with IAS 
will also become more complex, and will increasingly require professionals able to integrate the ecological, social, and economic dimensions of the problem into strategies of prevention, early detection, rapid response, eradication, control, and management. In its Global Strategy on Invasive Alien Species, the Global Invasive Species Program (GISP) identifies the development of university curricula on IAS as a priority strategic response for building management and research capacity on the issue (McNeely et al., 2001). The Global Strategy advocates the creation of national Centres of Excellence to promote research and education on invasion biology from a cross-sectoral and multidisciplinary perspective. Similarly, the international Convention on Biological Diversity (CBD) recognizes the importance of education and training on IAS, and highlights universities as being uniquely positioned to strengthen biodiversity knowledge (United Nations, 1993). Curiously, Canada's National Invasive Alien Species Strategy does not mention the role of post-secondary education in combating IAS. The National Strategy focuses on public education as a high priority, and does indicate that the development of educational curricula is important, although the level of this training is not specified (Government of Canada, 2004).

Post-secondary programs on IAS exist internationally, yet Canada is currently lacking comprehensive and interdisciplinary university curricula on the subject. As a result, our ability to successfully address the increasing complexity of IAS issues is seriously hindered. No degree or diploma programs are currently offered that specifically address IAS issues. Many programs nationwide do focus on global change and global environmental problems, such as climate change, pollution, human overpopulation, sustainability, and land-use patterns, and some adopt an interdisciplinary approach. However, while IAS issues interact and overlap with these topics, attention to IAS is often cursory or completely absent within Canadian environmental programs. Few courses are dedicated primarily to IAS issues, and those that are typically take a strictly ecological approach. IAS currently do not figure within curricula on human security or disaster management.

In contrast, several international graduate-level programs were identified in this study that focus significantly on interdisciplinary training of IAS issues. Although the approach differs somewhat from one institution to the next, the programs do have several characteristics in common. In particular, the three U.S. IGERT programs promote interdisciplinary and transdisciplinary learning by emphasizing: (i) team-teaching by faculty from diverse backgrounds (e.g., anthropology, biology, economics, engineering, law, sociology, and public health); (ii) participation of external partners from beyond academia (e.g., representing government, non-governmental organizations, and the private sector); and (iii) opportunities to apply training to real-world problems in an interdisciplinary context (e.g., through co-operative field research on socially and environmentally relevant issues). By teaching students that complex environmental problems can only be solved with the coordinated effort of scientists, policy-makers, and the wider community, and by providing students with the skills to forge these linkages, the IGERT programs aim to bridge the traditional gaps between science and policy, and science and society.

The absence of comprehensive IAS training at Canadian universities cannot be attributed merely to possible limited financial resources or time to develop programs. IAS are acknowledged to be as harmful to the environment, economy, and society as other global stressors, such as climate change and pollution, yet they do not garner equal attention in university curricula. Furthermore, recognition of the impacts of biological invasions is nothing new. The seminal book The Ecology of Invasions of Animals and Plants (Elton, 1958) launched the field of invasion ecology over 50 years ago, and research in this discipline has increased ever since.

The unbalanced coverage of IAS in post-secondary education, in comparison with other global stressors, reflects the lack of prominence of IAS issues in society at large. For example, despite the strong link between liberalization of world markets and increases in biological invasions, the prevention of IAS threats is rarely at the forefront of trade discussions (Perrings et al., 2002; Chornesky \& Randall, 2003). Both public awareness of the scope of the IAS problem, and political will to address it, are scarce (Claudi, Nantel, \& Muckle-Jeffs, 2002; Lodge et al., 2006; Stoett, 2007). This disconnect between the severity of the IAS problem, and our response to it, undoubtedly stems from several key features of IAS, namely that they tend to be hard to predict, that their impacts typically are not immediately apparent (and tend to be spread across many stakeholders), and that, once established, IAS are virtually impossible to eliminate (Horan, Perrings, Lupi, \& Bulte, 2002; Lodge et al., 2006; Pejchar 
\& Mooney, 2009). Unlike climate change or pollution, IAS do not offer easily identifiable targets for solving the problem (e.g., reduce $\mathrm{CO}_{2}$ or point source emissions).

Education can be a powerful tool for improving our strategic approach to IAS issues. But the scale of the response must match the scale of the problem. Recognition of the magnitude of the threat, and its wide-ranging implications for the environment, economy, and society, must be reflected within the curricula of post-secondary institutions in Canada, much like climate change has been within recent years. In fact, there are several parallels between the two issues which may be useful to consider in the design of IAS educational programs. For example, both climate change and IAS have caused unprecedented rates of environmental change, are global in their extent, are addressed by international conventions, and have the ability to cause significant damage to humans and the environment. The striking difference, however, is that it is still possible to halt the trend of increasing carbon dioxide in the atmosphere, but reversal of IAS is unlikely once they become established in new locations (Mooney \& Hobbs, 2000).

\section{Developing Post-Secondary Curriculum on IAS in Canada}

The framework is already in place for the integration of IAS training more fully into post-secondary curricula in Canada. More than 200 undergraduate, 100 graduate, and 30 diploma programs dedicated to addressing global environmental issues exist at Canadian universities , and many emphasize an interdisciplinary approach. Several graduate programs in disaster management are also offered across the country. In addition, Canada is home to many scientific experts on IAS, many of whom teach and conduct research at universities and work collaboratively with partners outside academia. The federal government also currently funds the Canadian Aquatic Invasive Species Network (CAISN), a national group of IAS specialists working to improving the science of prediction and prevention of aquatic invasions in Canada. CAISN is made up of 34 researchers from 21 partner universities and five federal laboratories, as well as up to 50 graduate students and post-doctoral fellows. Although CAISN has no formal educational curriculum, students do receive training in invasion biology through their thesis research. Furthermore, the Ontario and federal governments recently announced the creation of an Invasive Species Centre in Sault Ste. Marie, which will serve as a research facility for coordinating efforts to control the spread of IAS at provincial and national levels. Moreover, the Secretariat of the CBD, whose role is to support the implementation of the convention, coordinate international efforts, and act as an information clearinghouse on biodiversity issues, is located in Montreal.

Numerous books addressing IAS from an interdisciplinary perspective also exist that could form the basis of IAS curriculum development in Canada. For instance, Ecology and Control of Introduced Plants (Myers \& Bazely, 2003) provides historical, ecological, and sociological background on invasive plants; Invasive Species in a Changing World (Mooney \& Hobbs, 2000) explores the interaction of IAS with other elements of global change, as well as their social and economic impacts; Invasive Species and Biodiversity Management (Sandlund, Schei \& Viken, 2001) combines ecological, epidemiological, cultural, and management aspects of the IAS issue; while Alien Invaders in Canada's Waters, Wetlands, and Forests (Claudi, Nantel, and Muckle-Jeffs, 2002) offers a comprehensive overview of the situation in Canada.

Using established international IAS educational programs outlined in this paper as models, an ideal Canadian curriculum should include several key components. First, it should adopt both an interdisciplinary and transdisciplinary approach to teaching, so that the full spectrum of causes, impacts, and management implications of IAS are addressed. For example, an understanding of both the ecological and socio-political drivers of biological invasions is needed to inform prevention efforts (Reaser, Meyerson, \& Van Holle, 2008). Similarly, effective IAS risk assessment requires input from a wide range of disciplines, including ecology, economics, and health (Bradley, Blumenthal, Wilcove, \& Ziska, 2010). Moreover, consideration of the perspective of non-academics, who are either directly affected by IAS (e.g., farmers, fishers), or who work on prevention or control of IAS (e.g., land managers), is crucial when developing policy and action initiatives. To further emphasize the multi-faceted dimensions of the IAS problem, biological invasions could be framed as a human security issue, and analogous to natural disasters in how they should be managed.

Faculty should be drawn from a variety of university departments (e.g., biology, economics, history, law, philosophy etc.) to teach courses jointly as interdisciplinary teams. Several core courses 
could form the basis of the program, on topics such as the "Biology/Ecology of IAS," "Socio-Economic Impacts of IAS," "IAS Policy and Management," and "Interdisciplinary Responses to Global Stressors." Additional training modules could be developed to round out interdisciplinary training, covering subjects like i) communicating science to the general public, media, and policy-makers; ii) environmental economics and ecological valuation; iii) translating science into policy; iv) and problem solving in an interdisciplinary or transdisciplinary environment.

Upon completion of coursework, students would then take part in interdisciplinary field research encompassing a diversity of research areas (e.g., biology, economics, health, policy, resource management etc.) and a range of project participants (e.g., scientists, land managers, policy-makers, farmers, educators etc.). Non-academic institutions involved with IAS work, such as the Secretariat of the CBD and the Invasive Species Centre, could provide resources and expertise (e.g., the former on international law and prevention efforts, the latter on Canadian control efforts). Possible topics for field research projects include IAS management and policy in the context of climate change, impacts and management of IAS in the developing world, developing an IAS public education campaign, and developing IAS elementary curriculum.

The final component of a Canadian IAS curriculum should be an internship either in the public or private sector, working on IAS issues. Students might be placed, for example, with CAISN researchers, to conduct research on predicting and preventing aquatic invasions, or with the CBD Secretariat to address international aspects of prevention and management.

The program could be offered as a two-year Master's degree (with coursework the first year, followed by field research and internship the second year) or a four-year PhD (with field research developing into a thesis, and with perhaps a longer internship period).

\section{CONCLUSION}

Wherever IAS are found there is a need for education on how to deal with them. In this paper, we provide a preliminary evaluation of how well we are accomplishing this training at the post-secondary level in Canada, and examine several international examples of IAS educational programs. We recommend that a graduate-level interdisciplinary degree program on IAS be developed at one or more Canadian universities. The program should combine both course-work and practical experience, and should expose students to both academic and non-academic perspectives on IAS issues. Several existing institutions could be involved in delivering the program, and partnerships could also be sought with government (e.g., Ministries of Agriculture, Environment, Health, Natural Resources) and non-governmental organizations.

Our research is meant as a general overview of the issue of IAS training in higher education, and as such, does not make detailed, technical comparisons of existing programs (e.g., by measuring pedagogy or educational outcomes such as progression to a higher degree or job placement). A logical next step would be for a more analytical investigation of university teaching on IAS to identify strengths and weaknesses of various approaches.

Many opportunities exist in Canada to develop comprehensive interdisciplinary training on IAS issues. The time has come to expand current efforts and educate more widely on IAS issues at the post-secondary level. By acknowledging the urgency of the IAS challenge and mounting an appropriate educational response, we will strengthen Canada's preparedness to face IAS challenges in the future.*

\section{REFERENCES}

Bradley, B. A., Blumenthal, D. M., Wilcove, D. S., \& Ziska, L. H. (2010). Predicting plant invasions in an era of global change. Trends in Ecology and Evolution 25(5), 310-318.

Carney, J. , Chawla, D., Wiley, A., \& Young, D. (2006). Evaluation of the initial impacts of the National Science Foundation's Integrative Graduate Education and Research Traineeship Program. Final Report. Bethesda, MD: Abt Associates Inc.

Chornesky, E. A., \& Randall, R. M. (2003). The threat of invasive alien species to biological diversity: Setting a future course. Annals of the Missouri Botanical Garden 90(1), 67-76. 
Claudi, R., Nantel, P., \& Muckle-Jeffs, E. (2002). Alien invaders in Canada's waters, wetlands, and forests. Ottawa, ON: Natural Resources Canada, Canadian Forest Service, Science Branch.

Colautti, R. I., Bailey, S. A., van Overdijk, C. D. A., Amundsen, K., \& MacIsaac, H. J. (2006). Characterised and projected costs of nonindigenous species in Canada. Biological Invasions 8(1), 45-59.

Enserink, M. (1999). Biological invaders sweep in. Science 285(5435), 1834-1836.

Elton, C. S. (1958). The ecology of invasions by animals and plants. London, UK: Methuen.

Godemann, J. (2006). Promotion of interdisciplinary competence as a challenge for higher education. Journal of Social Science Education 5(2), 51-61.

Godemann, J. (2008). Knowledge integration: A key challenge for transdisciplinary cooperation. Environmental Education Research 14(6), 625-641.

Government of Canada. (2004). An invasive alien species strategy for Canada. Ottawa, ON: Author.

Government of New Zealand. (2003). Tiakina aotearoa. Protect New Zealand. The biosecurity strategy for New Zealand. Wellington, NZ: New Zealand Biosecurity Council.

Haigh, M. (2005). Greening the university curriculum: Appraising an international movement. Journal of Geography in Higher Education 29(1), 31-48.

Horan, R. D., Perrings, C., Lupi, F., \& Bulte, E. H. (2002). Biological pollution prevention strategies under ignorance: The case of invasive species. American Journal of Agricultural Economics 84(5), 1303-1310.

Larson, B. M. H. (2007). An alien approach to invasive species: Objectivity and society in invasion biology. Biological Invasions 9(8), 947-956.

Lodge, D. M. (1993). Biological invasions: Lessons from ecology. Trends in Ecology and Evolution 8, 133-137.

Lodge, D. M., Williams, S., MacIsaac, H. J., Hayes, K. R., Leung, B., Reichard, S., ... McMichael, A. (2006). Biological invasions: Recommendations for U. S. policy and management. Ecological Applications 16(6), 2035-2054.

Ludwig, D., Mangel, M., \& Haddad, B. (2001). Ecology, conservation, and public policy. Annual Review of Ecology and Systematics 32, 481-517.

McNeely, J. A. (2000). The future of alien invasive species: Changing social views. In H. A. Mooney \& R. J. Hobbs (Eds.), Invasive species in a changing world (pp. 171-190). Washington, DC: Island Press.

McNeely, J. A (2001). The great reshuffling: How alien species help feed the global economy. In 0. T. Sandlund, P. J. Schei, \& Å. Viken (Eds.) Invasive species and biodiversity management (pp. 11-31). Boston, MA: Kluwer Academic Publishers.

McNeely, J. A., Mooney, H. A., Neville, L. E., Schei, P. J., \& Waage, J. K. (Eds.). (2001). A global strategy on invasive alien species. Gland, Switzerland: International Union for Conservation of Nature (IUCN) in collaboration with the Global Invasive Species Programme.

Mooney, H. A., \& Hobbs, R. J. (2000). Invasive species in a changing world. Washington, DC: Island Press.

Myers, J. H., \& Bazely, D. R. (2003). Ecology and control of introduced plants. Cambridge, UK: Cambridge University Press.

Norton, B. G. (1998). Improving ecological communication: The role of ecologists in environmental policy formation. Ecological Applications 8(2), 350-364.

Noss, R. F. (2007). Values are a good thing in conservation biology. Conservation Biology 21(1), 18-20.

Pejchar, L., \& Mooney, H. A. (2009). Invasive species, ecosystem services and human well-being. Trends in Ecology and Evolution 24(9), 497-504. 
Perrings, C., Williamson, M., Barbier, E. B., Delfino, D., Dalmazzone, S., Shogren, J., ... Watkinson, A. (2002). Biological invasion risks and the public good: An economic perspective. Conservation Ecology 6(1). Retrieved from http://www.consecol.org/vol6/iss1/art1.

Pfeiffer, J. M., \& Voeks, R. A. (2008). Biological invasions and biocultural diversity: Linking ecological and cultural systems. Environmental Conservation 35, 281-293.

Reaser, J. K., Meyerson, L. A., \& Van Holle, B. (2008). Saving camels from straws: How propagule pressure-based prevention policies can reduce the risk of biological invasion. Biological Invasions 10, 1085-1098.

Ricciardi, A., Palmer, M. E., \& Yan, N. D. (in press). Managing biological invasions as natural disasters. BioScience.

Sala, O. E., Stuart Chapin III, F., Armesto, J. J., Berlow, E., Bloomfield, J., Dirzo, R., ... Wall, D. H. (2000). Global biodiversity scenarios for the year 2100. Science 287, 1770-1774.

Sandlund, O. T., Schei, P. J., \& Viken, Å. (Eds.) (2001). Invasive species and biodiversity management. Boston, MA: Kluwer Academic.

Sax, D. F., Stachowicz, J. J., Brown, J. H., Bruno, J. F., Dawon, M. N., Gaines, S. D., ... Rice, W. R. (2007). Ecological and evolutionary insights from species invasions. Trends in Ecology and Evolution 22(9), 465-471.

Simberloff, D. (2002). Ecological and economic impacts of alien species: A phenomenal global change. In R. Claudi, P. Nantel, \& E. Muckle-Jeffs (Eds.) Alien invaders in Canada's waters, wetlands, and forests (pp. 29-39). Ottawa, ON: Natural Resources Canada, Canadian Forest Service, Science Branch.

Simberloff, D., Parker, I. M., \& Windle, P. N. (2005). Introduced species policy, management, and future research needs. Frontiers in Ecology and the Environment 3, 12-20.

Sterling, S., \& Witham, H. (2008). Pushing the boundaries: The work of the Higher Education Academy's ESD Project. Environmental Education Research 14(4), 399-412.

Stoett, P. J. (2007). Counter-bioinvasion: Conceptual and governance challenges. Environmental Politics 16(3), 433-452.

Strauss, S. Y, Doremus, H., Griesemer, J. R., Grosberg, R. K., \& Rice, K. J. (2007). IGERT: Responding to Rapid Environmental Change (REACH): From genes to ecosystems, science to society. Project proposal submitted to National Science Foundation, October 5, 2007.

Sutherst, R. W. (2000). Climate change and invasive species: A conceptual framework. In H. A. Mooney \& R. J. Hobbs (Eds.) Invasive species in a changing world (pp. 211-240). Washington, DC: Island Press.

Tanentzap, A. J., Bazely, D. R., Williams, P. A., \& Hoogensen, G. (2009). A human security framework for the management of invasive nonindigenous plants. Invasive Plant Science and Management 2(2), 99-109.

United Nations Environment Program. (1993). Convention on Biological Diversity. Concluded on June 5, 1999, came into force December 29, 1993. UNEP Vol. 1760, No.30619.

Williamson, M. H., \& Brown, K. C. (1986). The analysis and modeling of British invasions. Philosophical Transactions of the Royal Society B 314(1167), 505-522.

\section{ACKNOWLEDGEMENTS}

We gratefully acknowledge the assistance of John Lindsay (Brandon University); Danielle Wood (Dalhousie University); Peter Williams (Landcare Research New Zealand); Sarah Davies (Stellenbosch University); Imogen Bassett (University of Auckland); Stephanie Chang (University of British Columbia); Carole Hom (University California-Davis); Mike Braysher, Stephen Dalla Costa and Thomas Heinsohn (University of Canberra); Theresa Burg (University of Lethbridge); Ginna Anderson (University of Notre Dame); Art Freeden and Brenda Janzen 
(University of Northern British Columbia) and Brendon Larson (University of Waterloo). We appreciate the comments of Lesley Andres and three anonymous reviewers on an earlier version of this paper, and thank Iain Paterson for help with the French translation. We also thank the Government of Ontario's Ministry of Research and Innovation and York University for providing funding for this project.

\section{CONTACT INFORMATION}

Andrea L. Smith Institute for Research and Innovation in Sustainability

York University

349 York Lanes 4700 Keele Street

Toronto, Ontario

Canada, M3J 1P3

Email: geckoals@yorku.ca

Andrea Smith is a post-doctoral fellow at York University's Institute for Research and Innovation in Sustainability (IRIS). Her research interests include investigating Canada's preparedness to deal with the interdisciplinary threats of invasive alien species through policy and education, as well as the interactive effects of climate change and invasive alien species. Andrea has conducted research in ecology, evolutionary genetics, conservation biology and natural heritage policy. She has published articles in both scholarly journals and popular magazines on a wide range of environmental issues.

Dawn Bazely is an Associate Professor of biology at York University and Director of IRIS. Her research publications number over 60 articles, chapters, and books, including Ecology and Control of Introduced Plants: Evaluating and responding to invasive plants, 2003 (monograph with Judith Myers), and the forthcoming, Environmental Change and Human Security in the Arctic, 2011 (co-edited with Gunhild Hoogensen and Andrew Tanentzap). Dawn and her students study plant-animal interactions, from temperate to arctic regions, and associated issues. Most recently, she led the Canadian section of the International Polar Year project, GAPS, Gas, Arctic Peoples and Security.

Norman Yan is a Professor of biology at York University in Toronto. He works in a formal partnership with the Ontario Ministry of the Environment on the effects of multiple interacting stressors, including invasive alien species, on Ontario's lakes. This research has led to more than 100 publications and garnered provincial and national awards for excellence in aquatic research. Yan teaches in aquatic ecology, restoration ecology, and the biology of environmental management. 